\title{
Building of an Internet based Industry Platform to Leverage the Aging Industry Development
}

\author{
Dan Liu',a \\ ${ }^{1}$ Business School of Jianghan University, Wuhan, Hubei, China \\ a136782581@QQ.com
}

Key words: Ageing, the third age communities, the Internet

\begin{abstract}
The aging trend has brought major changes in the structure of population and social supply \&demand. With the rocket of the elderly population, the aging industry is expected to become a new growth for economic development. However, the development of China's aging industry is facing the dilemma of weak industrial basic, supply and demand mismatch as well as unsustainable profitability. By building a virtual community which based on the Internet platform, products and services of community medical care, senior university, senior professional products and remote services are integrated into an interconnected and intelligent service network that form a modern model of the aging industry, then make it into a model that helps to promote China's economic restructuring New growth area.
\end{abstract}

\section{Introduction}

A variety of data shows that China has entered the aging era. In the case of aging, most scholars view it as the opposite of " demographic dividend ". With more research and work, the focus on attention has changed from social problems of / with economic structure evolution, and the views which transfer the aging requirements into a new economic growth point [1] [2] and combine the use of Internet services and intelligent technology with aging economy [3]. In reality, whether from the perspective of the government or the public, providing for the aged is still regarded as a " sunset care ", the supply of consumer goods and services for aging, which is far from forming an industrial scale matching the population. Based on the census data and industry research conducted in recent years in our country, paper analyzes the imbalances and problems in the economic structure brought by the aging population in our country. According to the characteristics of weakness and causes of the aging industry, according to the modern economic theory and the new advantages of the Internet economy, proposed a new economic model of building an open industry platform based on the Internet and developing the aging industry.

\section{Core concept definition}

Population Aging: Population aging refers to the process of the rising proportion of the elderly population in the total population resulting from the reduction of the birth rate and the prolongation of average life expectancy, and the high proportion of the elderly population as shown by the social population structure. It is generally accepted in the international community that over the age of 60 accounting for $10 \%$ of the population of a country, or aged 65 accounting for $7 \%$ of the population, which mean that the population of this country is in an aging society .

Third-Age Communities: In some European countries, people are accustomed to dividing their lives into four successive age groups: children and adolescents; careers and earning; retirement; dependency. " Third Age " refers to the retirement period. It is valued because the " third age " after retirement accounts for one-third of one's life in terms of time. During this time period, although one has retired, the demand and productivity have not disappeared. At this stage, people with low life pressure and low family burden have greater possibility and convenience in developing their own talents and interests and play an important role in fully realizing the value and significance of life. If we can manage the state of life at this stage, we can effectively improve the quality of life and shorten the period of dependency on the fourth age. The " third-age community " discussed in 
this article refers to a social group differs from other age groups due to differences in age, culture and living conditions.

\section{Aging - the development of security and difficulties}

Technology and production progress offer the conditions for human beings to keep up more population with limited resources and less labor comments. The progress of medical service has further improved the people's health level and extended the retirement years. In addition, the cumulative effect of " one child policy ", the new population declines year by year, China's population distribution shows a gradual and backward trend, the aging of the population problems continue to emerge. According to a research, the proportion of elderly population of Wuhan will reach $22.55 \%$ in 2016. A large, " the third age community " is about to form, accounting for the proportion of 1/4 Wuhan population. The phenomenon of aging is the inevitable result of the welfare of economic development, and it also brings pressure on the traditional economic model.

On the one hand, aging has brought about a change in population structure. The rise in the dependency ratio has rapidly closed our short-term demographic dividend window. The living security, equal rights and development demand of the aging population have gradually become a new problem of social development. At the same time, with the expansion of the population of the elderly population, the structure of social needs is also undergoing major changes. The aging industry is expected to become a new growth point in economic development and conducive to promoting the development of the tertiary industry. The upgrading and extension of the aging industry will lead to wider application of new technologies and even push a new wave of innovation. On the other hand, the arrival of aging will make the economy of our country facing to labor to force shortage, low efficiency of production and supply of human resources and labor tension, from the supply side to restrict the development of China's labor-intensive industries and service economy. Traditional economic advantages will be undermined.

In urban areas, the relatively well-established public facilities and convenient living conditions are the living environment on which elderly people depend. As a gathering place for economic activities, some big cities will also continue to attract influx of young people, which will inevitably lead to pressure on the allocation of urban resources, accompanied by rising prices. Once the existing pattern cannot balance various conflicts of interest, the most dynamic population may make adverse choices and some cities will face the risk of being hollowed out.

All this is a warning to us that the effects of aging on economic development and social stability will be comprehensive and profound. We must be prepared to take part in and lead it to the correct direction before its development has yet to become a huge force of inertia.

\section{Aging industry under the old mode inertia.}

The arrival of the aging society calls for an aging industry. However, our investigation has found that the development of China's aging industry is now facing the dilemma of weak industrial foundation, mismatch between supply and demand, and difficult to make profits.

At present, the old age industry is mainly distributed over three aspects: old-age care, old-age health care and old-age tourism. The first to develop are the old-age care, which is not related to its livelihood characteristics. However, for a long time, old-age care has been regarded as a " relief project " in the category of public welfare or obligation. The service objects of the Institutional pension model led by the government led are the destitute people that cannot take care of themselves. A large number of non-poor old--age people that cannot take care of themselves mainly taking the means of home-based care. But when other young members of the family go out to work, the safety and convenience of the elderly in the home would be a problem. Therefore, people began to hope that the community pension model would be supplemented. However, the aging members are not the main service objects of the current community system, and the " community old-age cares " are often carried out in the form of public welfare activities and lacks continuity. Old age health care and old age tourism is an emerging market developed in the last 20 years, playing a 
positive role in meeting the multi-level needs of the elderly. But because of their smaller size, they have been dependent on drugs, food and tourism industries. The prominent problem of this development mode lies in the lack of sufficient market information and the standardization and guidance of industrial policies. Together with the marginalization factors, the development of these markets has been in a state of repression. Relate surveys show that the needs of the third age group after retirement are diverse and multi-layered. The existing industry is difficult to meet the increasing demand. China's aging industry came out from the traditional mode in many areas have shown vulnerable characteristics [4].

\subsection{The lack of payable demand}

The lack of the ability to pay for demand is the basic driving force for any industry under market conditions. Among them, desire and ability to pay are two basic factors. However, the current consumption demand of our country is a dammed lake, which is blocked by the ability to pay. Although China's population of the age of 65 in 2013 has exceeded 130 million, accounting for $9.7 \%$ of the total population ["China Statistical Yearbook " 2014]. (The population of people over 65 years old in Wuhan is 958 thousand, accounting for $11.65 \%$ of the total population) [Wuhan statistical yearbook, 2014]. However, the average income level of the population is low, about (2000 - 3000 ) yuan / month, and with the high expenditure of preventive expenditure, the actual consumption ability of the elderly population is lower than their income level. On the other hand, there is a big gap between the demand of the elderly population and the market supply. " Ten City million elderly home-based cares / cared status survey " was organized by the national home-based care for the aged status survey activities committee from February to August in 2013, which showed that the average market price of housekeeping is 20 yuan / hours, while older people can afford 15 yuan / hours ; daycare market price is 50 yuan a day on average, older people can afford 40 yuan a day. The cost and price conflict between supply and demand is undoubtedly the basic economic factor to curb the consumption of the aged.

\subsection{The lack of value added elasticity}

Due to insufficient affordability and the changing social roles, aged people tend to pay more attention on basic demand and are sensitive to price [6]. This leads to that the prices of basic consumer goods tend to be determined by cost. On the other hand, the market cannot recognize industry innovation. The products and services are single, the added value is meager, and the profit is little.

\subsection{Profits are lower than the social average for a long time}

Due to the above reasons, the profits of the aged industry are lower than the social average for a long time, and it is difficult to achieve the expansion and development through effective management. Unwilling to invest and unable to invest, the aging industry has been in a weak growth status.

\subsection{Employees have low level of human capital}

According to our survey, the number of nursing staff aged over 40 accounted for $64 \%$ of the pension service institutions interviewed, and the number of laid-off workers and rural workers accounted for $74 \%$. As for education, more than $90 \%$ of the nursing staff graduated from middle school or below. High school (including technical secondary school) education only accounted for $9.5 \%$. In addition, nursing staff has the feature of low number and big turnover. In private old-age care facilitating institutions, one out of every three nursing worker is from the other side of the country. The low human capital makes it difficult for the elderly industry to obtain the inherent energy of industrial innovation. However, lack of innovation and low profit level is an important reason to prevent high-level human capital from entering the aging industry. 


\section{The prospects of the aging industry in the transition period}

The advent of aging is a real problem of our country. It has not only changed the demographic structure, but has also changed our economy in terms of demand and supply. In the economic transition to China, the sensitive capital market is detecting this shift. According to the stock market research report, the pension-related large-scale consumer industry has become an important area for investment capital allocation. Central enterprises, insurance, foreign capital and other domestic and foreign capital have invested in the elderly service market. For example, Cherish Yearn built 800 pension apartments in Shanghai. Fortress Investment, the largest pension agency in the United States, plans to invest 1 billion U.S. dollars to enter the aging service market in China. The large-scale foreign-funded pension project - the Zhenhai LR high-end pension project has also introduced the United States Sunrise Living Buffalo Grove, a pension service chain, operates and manages. [7] The inflow of various capitals apparently saw the future prospects of the aging industry.

The government's policy reforms at the demand side have effectively improved the consumption capacity of the elderly population. The popularization of the pension system and the comprehensive construction of the medical and social insurance system not only ensure the livelihood of the people, but also release a great deal of potential demand. It is estimated that the proportion of the elderly population will exceed $10 \%$ in 2020 , total consumption will reach $2,450.5$ billion yuan (equivalent to $14 \%$ of total consumption in 2013 ), and this amount will reach $3,471.88$ billion yuan in 2025 (equivalent to 2013 total spending 19\%), accounting for for one-tenth of the total expenditure on household consumption. In 2030, the total consumption of the population of 2002 will only cover the total population of the whole country in 2002. [8].

As time goes on, the composition of the aging population has changed. The proportion of highly educated and high-income people has gradually joined the new aging population. This not only improves the consumption capacity of the aged population, but also changes the consumption structure of the aged population. In addition to the traditional necessities of life like medical care and health, entertainment, sports, tourism and financial services have also begun to enter the "Consumer basket" of the elderly; the industrial upgrading and innovation are facing new opportunities.

The trend of employment mobility and family miniaturization driven by the market economy has made the traditional self-help family retirement system difficult to sustain and has opened the door to market-oriented aging services. At the same time, the adjustment of the economic center of gravity has embarked on a path of shift from manufacturing to service industries. The characteristics of the aging industry, precisely for this transformation provide a vast territory.

However, although we have stood at the door of new opportunities, there are still many problems to be solved in how to open the door. The key is to reduce or transfer costs, and upgrade industry. With the help of Internet thinking, through the construction of a virtual community and interconnected intelligent services, the elderly industry will emerge from the disadvantaged predicament, and become a new growth field of economic transformation.

\section{Countermeasures and suggestions}

First, give full play to the government's " the second hand " role, through policies and regulations, industrial promotion policies, industry standards formulation, construction of public service platforms and other measures to guide industrial development and reduce industrial costs. Formulate an outline of the development of the aged industry to guide the development of the aged industry in general and global security policy; Formulate the policy of ensuring the rights and interests in the elderly, allocate the government budget and public resources to ensure the rights and interests of the elderly are effectively guaranteed; formulate industrial promotion policies on subsidies and taxes Incentives and other measures to reduce the initial cost of the industry to enter through the establishment of the relevant insurance funds and projects to reduce the investment and 
business risk of related businesses . Regulatory measures are guiding the industry standard and orderly development.

Second, the state-owned public welfare enterprises shall be established to build a wide-area "third-age community" intelligent platform based on residential communities and Internet technologies. With the help of the advantages of the interconnection intelligent network, the "member" assembly and big data methods will be used to improve the efficiency of market development and service and reduce the operating costs of the market.

Start public welfare projects and develop wearable mobile Internet products of the aged. Based on the community of residents, government subsidies are issued from elderly residents free of charge or at a discount, so as to lay the foundation for the "third-age community" based on the Internet to provide targeted follow-up services to follow-up aging products and services. Using the Internet as a means to connect social service institutions such as community hospitals and elder universities with "third-generation communities" so as to achieve the low-cost and facilitation of aging consumption and services; to open long-distance communication and exchange of services to the elderly relatives through wearable internet products Monitoring services, building a channel network of aged products and services with residents' communities and supermarket outlets as port to enhance the facilitation of aging consumption and provide a solid offline foundation for $\mathrm{O} 2 \mathrm{O}$ and tentative service models.

Third, Adhere to the principle of openness and actively introduce various types of enterprises to develop products and provide relevant services through the "third-generation community" intelligent platform. Facilitate access to social capital. Encourage enterprises of all kinds to access the platform and develop targeted and diversified products for the elderly consumption such as smart aids, remote care and medical care, home environment construction, related real estate and financial services, social entertainment and intelligent network services And services to promote industrial upgrading and innovation. Through the sharing of resources and interests with users, the independent service capability of the "third-generation community" intelligent platform can be realized. The investment and financing channels can be actively explored through module leasing, package sale or equity trading, To promote the continuity of investment in order to achieve the sustainable development of the project and the convenience of government funds to withdraw from the discretion.

Fourth, The volunteer services management system will be developed to realize the self-service cycle of " members of the third age community " through the method of accumulating points and working turnover. The service cost will be reduced while the human resources of the aged community will be fully developed and utilized to enhance social habits.

\section{Acknowledgement}

This paper is supported by the construction of "economic and industrial integration management of Urban Agglomeration", which is the dominant characteristic discipline group of Hubei provincial universities.

\section{Reference:}

[1] Yang Hong, Wu Changchun. Study on Countermeasures for the development of aged industry in China [J]. Productivity research, 2009, (5): 937 - 100.

[2] Yang Xiaoqi. Adjustment of industrial structure based on population aging. [J]. Scientific research on aging. 2013, (10): $30-36$.

[3] Wang Yongmei. Internet society and aging: opportunities and challenges [J]. Academic exchange, 2014, (8): 202 - 206.

[4] Guo Zhengmo, Wei Yufei. Support policy on aging industry weak characteristics and government aging industry of J. On the 2014, Tianfu, (3): 53 - 58. 
[5] Yang Xiaoqi. Study on the development of urban home care services in China based on the survey of ten urban elderly people [J]. Journal of aging research, 2014, (9): 36 - 43.

[6] Zhang Yan, Jin Xiaotong. Analysis of the restrictive factors of consumer behavior in China's aging population $[\mathrm{J}]$. Academic exchange, 2010, (10): 125 - 156.

[7] Wang Lili, Yang Xiaoqi. Analysis of the current situation, problems and trends of service industry for the aged in China [J]. Journal of aging research, 2015, (7): 6 - 17.

[8] Jin Xiaotong, Wang Tianxin. China's consumption of aged population: current situation and trends [J]. Population in Northwest China, 2012, (3): 23-3 